\title{
New Wellbeing Interventions in Primary Health Care: Reviewing the Relational Agenda
}

\author{
Geoffrey Meads* \\ Faculty of Health and Wellbeing, University of Winchester, UK
}

Received: 阱: September 25, 2018; Published: 眥: October 09, 2018

*Corresponding author: Geoffrey Meads, Professor of Wellbeing Research, Health and Wellbeing Research Group, University of Winchester, UK

\begin{abstract}
The growth in the volume and diversity of wellbeing practices as frontline service outlets poses fresh challenges for the adoption of new technical and scientific developments in health care. This short article reports the findings of a review undertaken in the United Kingdom of recent local evaluations of new social enterprises, in order to identify their formative relationships. Drawing on relational audit methodologies a gap analysis highlights three types of relationship where shortfalls hinder knowledge exchange across contemporary primary health care. The findings suggest that further research is required to understand the routes and mechanisms needed for the effective future integration of biomedical innovations into what are, in organisational terms, increasingly hybrid public health systems.
\end{abstract}

\section{Introduction}

In 2008 the World Health Organisation recognised the growing diversity of frontline services 'across sectors' as a key 'challenge in a changing world' for 'integrating public health actions into primary care' [1]. Its Annual Report then highlighted the pursuant risks of fragmentation and 'pervasive commercialisation' as new projects and programmes multiply. However, it placed these in the context of health authorities needing to respect 'citizen expectations' of choice, and to support more socially relevant services. In the ten years since this publication the growth in frontline service outlets has accelerated, with a new diversity of holistic health offers arising from such as mindfulness and naturopathy innovations. Most of these are sited in the private and voluntary sectors. The WHO report emphasised the threat of 'unregulated health systems' with which these locations can be associated. This threat is especially pertinent in relation to the promulgation of clinically effective and innovative procedures

In the UK there have been over 10000 new social enterprises created since central government promoted 'Big Society' initiatives to promote wellbeing and reduce demands on the National Health Service [2]. The formal responsibility for public health has been moved to local councils from the NHS in this period. Faith related agencies especially have responded to the national policy, which includes a wide range of options for organisational status. As a result community interest and oriented companies and social franchises have expanded through country wide developments in, for example, day care, food banks and street pastor schemes.

In the Winchester Anglican diocese - which covers a population of over one million people - this trend is illustrated by one of its social enterprises that now operates more than 120 Good Neighbour support services for older people [3]. In some major city suburbs wellbeing services occupy as much as a third of shop premises [4], with new migrants particularly prominent in the provision of alternative pilates and massage interventions.

In Winchester, as elsewhere, the 'changing world' which the WHO report highlighted has led to civic authorities re-defining their roles as custodians of 'experience' based cities. They no longer exist to just manage publicly funded services. In this context a number of local wellbeing agencies have commissioned the University of Winchester to undertake a series of evaluations and evidence syntheses over the 2015-2018 period. Their overall aims have been to identify good practice, assess performance and indicate opportunities for new interventions. Nationally this local development has been aligned to the creation of Academic Health Science Networks specifically dedicated to the rapid evaluation and adoption of new technical and scientific knowledge through partnerships between publicly and privately funded enterprises [5]. Locally the studies have included wellbeing agencies providing for children with long term medical conditions, dementia sufferers, single parent families, isolated seniors, substitute carers, new housing estates and homeless persons [6-10]. Together the aggregate data gathered in this research supplies a means of understanding better some of the relational issues which those involved in resourcing and regulating increasingly hybrid health systems now have to address.

\section{Analysis}

The ethnographic approach employed across the local studies referenced above has created a substantial database of observational records, interview notes, and collective responses from such as 
expert witness panels and focus groups. These have been analysed for this short review through the use of relational audit criteria drawn from standard works for inter-professional learning and cross practice collaboration in primary health care [11-13]. Because of the early stage of maturation of many wellbeing agencies the two fundamental audit criteria of directness and continuity have been used here as being most appropriate to identify where shortfalls in relevant relational strength exist. In summary directness covers such as face to face contact characterised by openness, honesty and a shared understanding of terminology; while continuity is defined by a regularity of contacts and communication over agreed time periods, with clearly defined horizons and mutually acknowledged processes for exchange. In the UK such relational audits have played a significant role in helping to facilitate the evolution of multidisciplinary NHS primary care trusts and clinical commissioning groups [14-15].

\section{Results}

The gap analysis was undertaken from the standpoint of applied research in and for primary health care. What are the key relationships required for the successful application of research findings in the modern practice of primary health care, where this incorporates conventional general medical services alongside new wellbeing provider outlets? By being non-functioning features, through their consistent absence across our local study settings, three gaps could readily be identified. These relationship shortfalls are first between a changing profile of senior decision makers; secondly between researchers themselves and wellbeing practices hosted by voluntary and private agencies; and finally between practitioners and professionals both within the latter organisations, and with NHS professionals. The overall impact is an increased difficulty for those involved in scientific and biomedical developments to achieve sufficiently representative data capture and appropriately targeted dissemination of findings.

The first type of relationship is that between new senior decision makers, such as elected mayors and cabinet leads for health matters in local authorities and GP members of the clinical commissioning groups which fund the majority of NHS care. Both groups have new multi-million pounds' accountabilities for resources but their paths simply rarely cross. Directness is minimal and continuity structures for meeting remain immature at best. As a result, typical queries encountered from councillors with public health responsibilities in our study included 'How are GPs recruited/deployed/distributed?' while GPs, for their part often commented that their workloads meant they could not keep abreast of the 'unitary' authority changes in their municipalities This gap in relationship appears to be further compounded by a similar level of ignorance for senior decision makers within organisations that have new health and wellbeing roles. Most striking of these were those between the departments of public health, trading standards and economic development in one local authority.

Although collectively responsible for the Council's positive manifesto on Community Wellbeing they simply did not meet at all on a face-to-face level to consider the (health) implications of new frontline service outlet applications in business and charitable premises. In one area the result was a decision to promote the growth of fast food shops to support the expansion of digital gaming companies. In another support to the dispersal of food books from a central site was driven by the economic argument for the maintenance of a sizeable low income labour force.

The second relationship shortfall is the gap that exists between researchers themselves and the wellbeing service sector. Directness and continuity do not exist operationally between the two. In our studies this was readily illustrated by the different approaches to governance issues. On the one hand one provider of a range of sports and spa services adamantly refused to provide any data on the grounds that it might be used for "official' regulatory purposes, while on the other two respite care social enterprises provided personal information on named older residents without prior consent and any reservations. The Wellbeing sector is often described as a 'stranger' by experienced medical researchers accustomed to the closed governance procedures and accountability structures of the NHS institution. It is easier still to get data just from within its boundaries. However, as several recent 'failed studies' commissioned by the National Institute for Health Research in England and Wales have demonstrated, this not enough. These studies have all fallen short on their remits because the researchers simply did not understand, for example, the different data capture regimes of such as independent sports clubs, youth centres and social housing settlements [16-18].

The final gap in relationships is simply that between the service providers themselves. Their profile is increasingly diverse. It is impossible, even at a local level for such as a nurse or general medical practitioner to know all that is being provided locally in the wellbeing sector.

As a result access to each appears to come through intermediaries. A chief officer of one well respected social enterprise described in one local study how he saw the provision of a comprehensive resource directory online as a critical source of competitive advantage over other historic charities. Another interviewee linked social action in the health care to the primacy of spiritual wellbeing as a potential source for church growth. More prosaically, a persistent feature of the local studies has been the presence across informal personal networks of personal trainers, pastors, mindfulness gurus and physiotherapists in signposting roles for other health and wellbeing services.

\section{Conclusion}

This review has pointed to important deficits in the relationship between the growing diversity of frontline health and wellbeing service providers. Collaborations between them remain at an early stage and uni-professional partnerships continue as the norm in most areas. The gap analysis suggests that basic elements of collaboration are often missing and there is a clear joint training need if such features of partnership working as reciprocal respect, shared values and breadth of understanding are to be taken forward [19]. For biomedical and health science research such progress in 
relationships would appear to be a prerequisite both for future data capture requirements and effective technology adoption strategies.

\section{References}

1. (2008) World Health Organization. Primary health care: now more than ever.

2. Lewin O, Swinson J (2014) New What Works centre for wellbeing.

3. Ralph N (2015) Good Neighbour Support Scheme: impact briefing.

4. Meads G (2016) Wellbeing agencies in the High Street: the rebirth of primary health care? The Open Public Health Journal 9(1): 31-37.

5. (2017) NHS England. About Academic Health Science Networks.

6. Meads G (2017) From pastoral care to public health: an ethnographic case study of collaborative governance in a local food bank. The Open Public Health Journal 10: 3-13.

7. Lees A, Payler J, Ballinger C, Faust S, Meads G, et al. (2017) Positioning children's voice in clinical trials research: a new model for planning, collaboration and reflection. Qualitative Health Research 27(14): 21622176.

8. Wilkinson E, Lees A, Meads G (2018) An evidence review on the effectiveness of interventions to reduce social isolation and loneliness in older people.

9. Meads G, Lees A, Tapson C (2016) Creational narratives for new housing communities: evidence synthesis. Housing, Care and Support 19(4): 105-114.

ISSN: 2574-1241

DOI: 10.26717/BJSTR.2018.09.001838

Geoffrey Meads. Biomed J Sci \& Tech Res

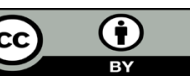

This work is licensed under Creative Commons Attribution 4.0 License

Submission Link: https://biomedres.us/submit-manuscript.php
10. Meads G, Lees A (2018) Developing community health and cohesion: an evidence synthesis for faith based agencies. In Almusaed A \& Almsaad A (Eds.). Public health: emerging and re-emerging issues.

11. Schluter M, Lee D (1993) The 'R' factor.

12. Barr H (1994) Perspectives on shared learning. Centre for advancement of interprofessional education.

13. Guy E (1986) Professionals in organizations.

14. Thomas P, Meads G, Moustafa A, Nazareth I, Stange KC, et al. (2008) Combined horizontal and vertical integration of care - a goal of practice based commissioning. Quality in Primary Care 16(6): 425-432.

15. Meads G, Meads P (2001) Trust in Experience. Transferable learning for primary care trusts. Radcliffe Medical Press.

16. Poortinga W, Rodgers S, Lyons R, Anderson P, Tweed C, et al. (2018) The health impacts of energy performance investments in low income areas: a mixed methods approach. Public Health Research 6(5).

17. Humphrey n, Hennessey A, Lendrum A, Wrigglesworth M, Turner A, et al. (2018). The PATHS curriculum for promoting well-being in children aged 7-9 years: a cluster trial. Public Health Research 6 (10).

18. Cummins s, Clark C, Renton A, Moore D, Bhui K, et al. (2018) Olympic regeneration in East London (ORIEL) study. National Institute for Health Research.

19. Meads G, Ashcroft J (2007) The case for collaboration in health and social care.

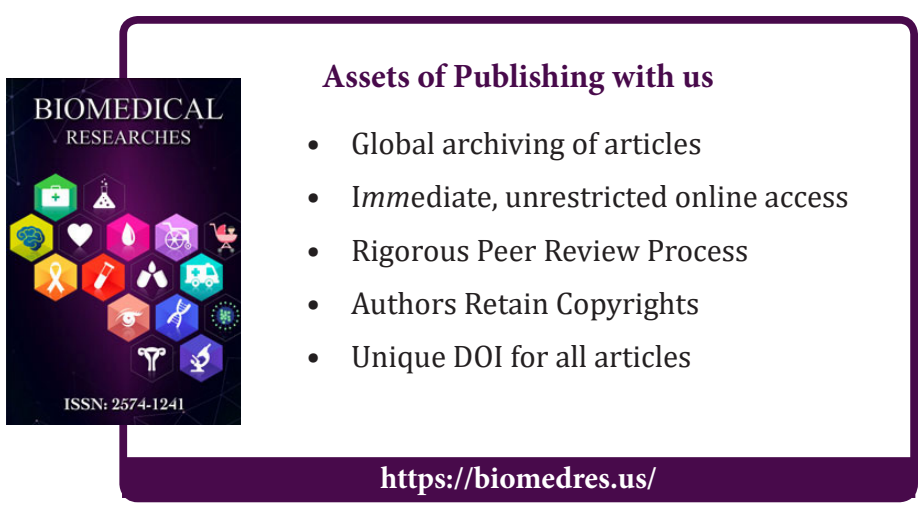

